\title{
Água e saúde: (des) integração entre vigilâncias e as lições da práxis
}

\author{
I 1 Ana Carolina Lanza Queiroz, 2 Laís Santos de Magalhães Cardoso, \\ ${ }^{3}$ Maria Teresa Zanatta Coutinho, ${ }^{4}$ Francisco Alves Guimarães, ${ }^{5}$ Léo Heller I
}

Resumo: A integração entre as ações intra e intersetoriais na área de saúde constitui desafio para gestores municipais, uma vez que prevalece no cotidiano do serviço a prática fragmentada da geração de dados e da análise dissociada das informações, resultando em obstáculos para um planejamento integrado. Um possível caminho para essa almejada integração funcional permeia o estabelecimento de canais de comunicação permanentes, possibilitando a programação conjunta das intervençôes envolvendo diferentes departamentos e setores. Uma avaliação do processo de articulação entre as vigilâncias epidemiológica e ambiental em saúde relacionada à água para consumo humano (Vigiagua), desenvolvida no município de Contagem-MG, identificou, por meio de análise do conteúdo de entrevistas realizadas com a coordenação da Vigilância em Saúde Ambiental, os condicionantes que interferem em sua institucionalização. A busca por maior domínio e valorização do trabalho pelos profissionais do Vigiagua, e a expectativa de agregar diferentes interlocutores e áreas de conhecimento na resolução de problemas comuns foram identificados como principais motivadores e facilitadores do processo. Em outro polo, foram detectados como pontos de estrangulamento: recursos humanos e financeiros; materiais insuficientes; falta de autonomia técnico-gerencial para o estabelecimento de canais de comunicação coesos; e incipiente prática de planejamento no serviço. Seminários e reuniōes caracterizaram-se como espaços de interação dialógica no serviço e possibilitaram uma aproximação de gestores do nível central com "executores" das instâncias locais. Entretanto, pleiteia-se que o estímulo para essa interlocução seja contínuo, o que demanda capacitação e desejo de gestores e profissionais para esse exercício.

> Palavras-chave: avaliação de programas e projetos de saúde; planejamento; programação; integração de sistemas; vigilância.

\author{
1 Enfermeira (UFMG), Mestre \\ em Saúde Pública (UFMG), \\ doutora em Saneamento, \\ Meio Ambiente e Recursos \\ Hídricos (UFMG), professora da \\ Pontifícia Universidade Católica \\ de Minas Gerais. Endereço \\ eletrônico: lanzaqueiroz@ \\ hotmail.com \\ 2 Enfermeira, especialista \\ em Saúde Coletiva (UFMG), \\ mestranda em Saneamento, \\ Meio Ambiente e Recursos \\ Hídricos (UFMG). Endereço \\ eletrônico: lilavate23@yahoo. \\ com.br \\ ${ }^{3}$ Doutora em Parasitologia \\ pela Universidade Federal de \\ Minas Gerais (2003). Endereço \\ eletrônico: ttzanatta@yahoo. \\ com.br \\ ${ }^{4}$ Mestre em Saneamento, \\ Meio Ambiente e Recursos \\ Hídricos pela Universidade \\ Federal de Minas Gerais (2000). \\ Doutorando do departamento \\ de Engenharia Química da \\ UFMG. Endereço eletrônico: \\ xicodafume@gmail.com \\ ${ }^{5}$ Doutor em Ciência Animal \\ pela Universidade Federal \\ de Minas Gerais (1995), com \\ Pós-doutorado realizado \\ na University of Oxford \\ (2005-2006). Professor do \\ Departamento de Engenharia \\ Sanitária e Ambiental da \\ Universidade Federal de Minas \\ Gerais. Endereço eletrônico: \\ heller@desa.ufmg.br
}


A Vigilância em saúde ambiental, complexa por sua natureza multidisciplinar e intersetorial, demanda uma abordagem que combine diferentes indicadores e áreas de conhecimento para tomada conjunta de decisóes e resolução de problemas afetos. No entanto, essa forma "não disciplinar de abordagem ainda constitui atividade fora do padrão" (BESSELAAR; HEIMERIKS, 2001), persistindo o desafio operacional e institucional de programá-las e desenvolvê-las agregando os diferentes atores e seus respectivos nichos de conhecimento.

Em 2008, a Coordenação Geral de Vigilância Ambiental (CGVAM)/ Ministério da Saúde (MS) propôs uma pesquisa para avaliar a viabilidade da integração entre os indicadores da Vigilância Epidemiológica (VE) e da Vigilância em saúde ambiental relacionada à água para consumo humano (Vigiagua), no intuito de direcionar ações de prevenção de doenças e promoção da saúde. No decurso do processo, constatou-se que essa abordagem integrada das questōes afetas às vigilâncias - visando utilizar indicadores sanitários e ambientais, mapas, softwares, entre outros instrumentos - perpassaria pelo estabelecimento de canais intersetoriais de comunicação e, também, pelo planejamento conjunto das ações por esses e outros departamentos e setores.

A interação dialógica aqui pretendida - inspirada na Teoria da Ação Comunicativa, de Habermas, e no planejamento e gestão em saúde, tal como formulado por Rivera - constitui o fio condutor do processo de interlocução entre as vigilâncias visando abranger a (inerente) complexidade da saúde, uma vez que permite englobar conhecimentos e articular diferentes instrumentos e experiências de outras áreas. A "iminência do diálogo" por meio de canais de interação eficazes e "fluxos de comunicação" passa a viabilizar/facilitar a busca do entendimento e a legitimação dos planos (RIVERA e ARTMANN, 2010), por meio da articulação intraorganizacional e o planejar integrado (RIVERA e ARTMANN, 1999), uma vez que as ações não mais se encerram naquele departamento por ela "responsável".

Nesse contexto, o artigo objetiva identificar quais os fatores intervenientes quiçá condicionantes - para o estabelecimento desses canais de interlocução entre a Vigilância Epidemiológica e o Vigiagua e, consequentemente, para a viabilização do planejamento conjunto de ações no âmbito municipal. Os principais desafios a serem transpostos para sua institucionalização no serviço são abordados com 
o objetivo de avançar a discussão e, ainda, possibilitar uma reflexão sobre a necessidade da prática articulada para a abordagem de questóes complexas, dentre as quais a qualidade da água para consumo humano e os riscos à saúde correlatos.

\section{Material e métodos}

Visando a atender ao objetivo inicialmente proposto pelo Ministério de Saúde, de trabalhar com municípios de diferentes portes populacionais (menor que 15 mil, entre 15 e 100 mil e maior que 500 mil habitantes), foram selecionados municípios integrantes da Região Metropolitana de Belo Horizonte (RMBH), apontados pelos profissionais da Secretaria de Saúde do estado de Minas Gerais como localidades cujo desempenho do Vigiagua, quando comparado com demais municípios do estado, encontrava-se em avançado processo de execução. A pesquisa, proposta pela Coordenação Geral de Vigilância em Saúde Ambiental (CGVAM/MS) aos autores deste artigo, integrantes da equipe executora da investigação científica, teve como objetivo elaborar, em parceria com os profissionais do Vigiagua e da VE da esfera municipal, estratégias para a integração entre os indicadores da qualidade da água para consumo humano e indicadores epidemiológicos. Optou-se por abordar, no presente artigo, o trabalho desenvolvido no município de maior porte populacional, designado como M1.

A pesquisa foi estruturada tendo como base as etapas da pesquisa-ação. Esse método qualitativo foi selecionado para avaliar a potencialidade de articulação entre o Vigiagua e a VE, uma vez que possibilita esclarecer e resolver os problemas e situaçôes identificadas, produzindo dados sobre os efeitos de uma mudança da prática antes, durante e depois da sua implantação (TRIPP, 2005). Os pesquisadores desempenharam diferentes papeis na pesquisa-ação, sendo responsáveis por introduzir a proposta de articulação entre as vigilâncias e de integração de indicadores, bem como por identificar os atores-chave nesse processo, coordenando as etapas da pesquisa-ação e mediando os espaços coletivos - seminários e oficinas. A pesquisa pode ser dividida em quatro etapas principais: fase exploratória, fase principal, fase de ação e fase de avaliação, não rigorosamente sequenciais, e seu planejamento pode ser flexível e passível de adequaçôes às necessidades dos participantes (THIOLLENT, 2008). No contexto específico desta pesquisa, optou-se pela inserção de uma fase preliminar, que abrangeu contatos e reuniões com a Secretaria de Estado de Saúde de Minas 
Gerais (SES-MG), para a seleção dos municípios participantes, a construção dos roteiros de entrevistas, sua aplicação em projetos-piloto e sua posterior adequação para aplicação nos campos selecionados. Após a execução dessa etapa preliminar, partiu-se para a identificação dos atores-chave, e realização de entrevistas (fase exploratória), com o intuito de avaliar as formas de atuação dos profissionais do Vigiagua e da Vigilância Epidemiológica, e o potencial de integração dos indicadores e informações gerados por essas instâncias.

Foram identificados como atores-chave no município os coordenadores da Vigilância em Saúde Ambiental e da Vigilância Epidemiológica, e, ainda, as referências técnicas dessas vigilâncias, totalizando cinco sujeitos. Esses profissionais foram entrevistados e suas falas gravadas em áudio para, posteriormente, serem transcritas na íntegra. A partir destas foi possível tomar contato direto e intenso com o material e, por conseguinte, com a realidade do serviço. Durante as entrevistas realizadas na fase exploratória, foi solicitado aos atores-chave que elencassem os sujeitos considerados indispensáveis para o êxito do processo de integração, posteriormente contatados e convidados a participar da pesquisa-ação. A partir das informações coletadas sobre as formas de atuação dos profissionais do Vigiagua e da VE, os canais de comunicação existentes e, ainda, os processos a serem desencadeados na instância municipal, foram organizadas e realizadas oficinas e seminários que objetivaram a pactuação das estratégias consideradas pelo grupo de participantes - núcleo de pesquisa e referências técnicas da Vigilância Epidemiológica dos Distritos Sanitários, profissionais da Atenção Básica, da Vigilância Sanitária, da Secretaria de Meio Ambiente e Secretaria de Limpeza Urbana - como fundamentais para o êxito do planejamento intraorganizacional e intersetorial (fase principal) e, então, operacionalizadas, na fase de ação.

Visando atender ao objetivo inicial, identificou-se como necessário o estabelecimento de canais de interlocução entre os departamentos e suas interfaces setoriais na instância municipal, na tentativa de favorecer o planejamento das ações, tendo por base a abordagem conjunta dos indicadores. As ações empreendidas objetivando essa interlocução e também aquelas pactuadas, e não colocadas em prática, foram avaliadas em momentos distintos, como reuniōes, oficinas e seminários, ora realizadas no nível central (Secretaria Municipal de Saúde), ora de maneira descentralizada, nos distritos sanitários de saúde (DSS) do município, configurando a fase de avaliação para 
análises pontuais do percurso, com validação ou refutação dos instrumentos e estratégias pactuadas ou implantadas.

Nesse contexto, foram criados espaços de comunicação (seminários avaliativos, primordialmente), que tiveram como objetivo gerar uma reflexão sobre os processos desencadeados após a fase de planejamento. Eles foram registrados em áudio e seguiram uma dinâmica similar: partiu-se de uma retrospectiva, seguida da aplicação do roteiro de perguntas e discussão das respostas por todos os envolvidos, culminando na elaboração de nova pactuação e cronograma de execução. A partir dessa avaliação em conjunto, novos passos e propostas, ou correçôes do percurso, bem como o cronograma para a sua execução, foram discutidos, gerando a espiral de etapas que estimula o processo contínuo de execução, observação, avaliação e recondução (LEWIN, 1946/1948) .

Uma entrevista final foi realizada com a coordenadora da Vigilância em Saúde Ambiental, que se destacou como a principal articuladora do processo de integração no município. Um roteiro semiestruturado foi elaborado e aplicado, sendo o momento de aplicação registrado em vídeo. As falas captadas foram transcritas, procedendo-se à análise de seu conteúdo e configurando, assim, uma avaliação qualitativa do processo empreendido, que "busca entender o objeto através da perspectiva dos envolvidos, ou seja, a sua interpretação vai de acordo com o contexto em que estes vivem e atuam" (MERRIAM, 2009).

Cumpre mencionar a intenção inicial dos autores em entrevistar também a coordenadora municipal da Vigilância Epidemiológica, importante elemento para a pesquisa no contexto trabalhado. Contudo, optou-se posteriormente por não incluí-la, uma vez que essa coordenação se manteve alheia ao processo após a realização do primeiro seminário, em função, principalmente, de outras demandas do serviço, como o controle de H1N1, dengue, não tendo, portanto, conhecimento suficiente acerca do trabalho realizado a ponto de emitir avaliações. Esse fato, ou seja, a dificuldade dos departamentos em se envolverem integralmente configurou-se como um dos obstáculos identificados na avaliação final do processo, e que é posteriormente detalhado nos resultados.

A observação participante, por meio de visitas realizadas quinzenalmente durante os dois anos de duração da pesquisa-ação, complementou os achados. A pesquisa, financiada pelo Ministério da Saúde, foi aprovada pelo Comitê de Ética em Pesquisa da Universidade Federal de Minas Gerais (COEP, parecer 431/08). 


\section{Resultados e discussão}

A fim de se identificarem os fatores intervenientes ou condicionantes da organização e da manutenção de canais de interlocução entre a VE e a Vigiagua no município, foi necessário primeiramente explorar os fatores que motivaram a discussão, a elaboração e a pactuação dessas estratégias de interlocução entre as vigilâncias no âmbito do serviço. Ou seja, foram investigados os motivos que levaram os profissionais que integram a Vigilância em Saúde a aceitarem o desafio de atuar de forma mais articulada.

Foi possível depreender, por meio das avaliações realizadas com o grupo de participantes, que a Vigilância em Saúde Ambiental, especificamente os profissionais do Vigiagua, aceitou a proposta de construção conjunta dos instrumentos de articulação, tendo como premissa a necessidade do cumprimento das metas previstas no arcabouço do programa. No entanto, mais do que o cumprimento de metas, os discursos evidenciaram que um enfoque que prioriza o compartilhamento dos indicadores e das informaçóes entre os diferentes departamentos e setores da instância municipal torna o processo de trabalho mais efetivo, uma vez que viabiliza intervençōes menos fragmentadas, amparadas em dados e informações de diferentes fontes.

A integração, ela gera eficiência. Você faz com mais eficiência, você tem mais segurança de que tá ampliando o trabalho. O parceiro no distrito passa a entender o que a gente tá fazendo. Além disso, a gente tem uma meta a cumprir, então eu acho que inicia para cumprir meta, isso eu acho que motiva

Nesse sentido, as falas tangenciam a busca por um processo de trabalho mais resolutivo, com valorização das atividades desenvolvidas, e sua divulgação para outras instâncias, com expectativa de atuação articulada, não somente entre os departamentos que compõem a Vigilância em Saúde, mas entre diferentes setores da instância municipal. Por meio das falas captadas, foi possível também inferir que a disposição e o desejo dos profissionais das diversas instâncias - central, local, distrital - de atuar de forma mais articulada constituem fator condicionante, que viabiliza ou impede a interlocução entre as vigilâncias no âmbito do serviço.

[...] houve um desejo de trabalhar junto, gerentes se mostraram super interessados, e tanto é que funcionou, né, gente? Eles deram condições pra gente fazer. No distrito 1 também houve um desejo, tava todo mundo lá. No distrito 2 não conseguiu avançar com a proposta por que a gerente logo saiu [em licença maternidade]. 
Foram investigados, ainda, durante a entrevista, os aspectos considerados facilitadores para a sedimentação da proposta de articulação na instância municipal. Destacaram-se o apoderamento da proposta pelos profissionais do serviço, o desejo de trabalhar em rede, descentralizando o planejamento para os níveis mais locais, e o maior aporte de conhecimento por aqueles que atuam na área.

Agora, eu acho que essa integração, à medida que a gente percebe que não dá para fa-
zer mais nada sem a "epidemio" do distrito, sem a zoonose do distrito, sem a diretora,
[...] a gente percebe que precisa fazer essa integração para que o trabalho tenha bons
frutos e cresça e que desenvolva [...]

Evidenciou-se que para o planejamento e execução das ações, geralmente de cunho multidisciplinar, foi necessário ao Vigiagua - nesse contexto particular, o núcleo articulador da ação - identificar e recorrer aos diversos parceiros municipais, organizando reuniões para aproximar os profissionais do nível central (Vigiagua e VE, principalmente) daqueles que atuam no âmbito local. Foram sendo estabelecidos, assim, os almejados espaços coletivos para a discussão, a deliberação e o planejamento conjunto (GUIZARDI; CAVALCANTI, 2010, p. 1249). Esses espaços comunicativos permitiram aos profissionais dos diferentes departamentos e setores partilhar questóes relativas ao seu objeto de trabalho, discutindo estratégias funcionais para seu êxito naquele território específico, através da multiplicidade de olhares. Essa interação dialógica constituiu, portanto, base elementar do processo, uma vez que possibilitou abranger a inerente complexidade da saúde de forma menos fragmentada, englobando conhecimentos e instrumentos, assim como experiências advindas das diferentes áreas participantes. Melo (2005) reforça a necessidade dos participantes da comunicação alcançarem esse entendimento sobre os seus planos de ação, de forma a coordená-los através de um acordo obtido por meio das definiç̧oes das situações que admitem um consenso.

Nesse sentido, como as vigilâncias possuem diferentes objetos de análise, técnicas e práticas diversificadas, uma vez que cabe à VE coletar, analisar, interpretar e disseminar as informações monitorizadas de determinados problemas de saúde (BUEHLER, 1998), e ao Vigiagua identificar situações de risco relacionadas à qualidade da água para consumo humano, comprovou-se necessário elaborar instrumentos específicos às vigilâncias que as conjugassem num plano comum. Corrobora-se, assim, com Habermas (1989, p. 41), que aponta a necessidade de "aproximação consensual com a finalidade de chegar 
à compreensão conjunta de uma coisa ou uma maneira de ver comum". No contexto específico desta pesquisa, os envolvidos se reuniram para definir quais os indicadores sinalizariam as áreas de risco para a ocorrência de morbidades de veiculação hídrica e quais apontariam os determinantes sanitários e ambientais de vulnerabilidade naquela localidade específica. Também foram discutidos os instrumentos/métodos necessários para sua visualização, como mapas e técnicas de georreferenciamento. Dessa maneira, incitou-se que uma rede de atuação fosse lentamente tecida e a proposta de integração, difundida para aqueles profissionais que passaram a fazer parte do processo, seja alimentando o banco de dados, seja divulgando o trabalho para outros profissionais e para a sociedade civil, de modo a angariar novos parceiros, na forma de encontros e reuniōes, da disponibilização de mapas e da capacitação de profissionais da rede, entre outras ações.

Assim, no decorrer da pesquisa-ação, foi possível perceber que atividades antes realizadas de forma pouco sistematizada, ou "mecânica", visando prioritariamente ao atendimento das metas ministeriais do PAVS e SISAGUA ("Programação das Ações de Vigilância em Saúde" e "Sistema de Informação de Vigilância da Qualidade da Água para Consumo Humano”), cederam espaço para a sistematização de dados e informações, a fim de facilitar o planejamento de ações envolvendo mais de um departamento.

Por que a gente fazia as coisas muito mecanicamente. [...] A gente tinha que fazer, mas não tinha uma clareza que isso podia funcionar [...]. Anteriormente era muito estanque, né? Só produzia dados. Como é que a gente ia planejar? [...] Por causa dessa clareza que a gente teve do planejamento. Não é clareza, né gente? É um caminho.

Apesar de identificada sua necessidade, o planejamento articulado demanda tempo, elaboração e manutenção de um banco de dados em que se conjuguem os inúmeros indicadores, alimentados pelos diversos departamentos e setores envolvidos, com interpretação dos dados, organização de estratégias com enfoques diferenciados e colaboração mútua. Instituem-se, portanto, alguns obstáculos (ou nós críticos) para a consolidação das estratégias de interlocução entre os departamentos, e que devem ser "conhecidos, analisados, enfraquecidos e removidos" (CAMPOS, 2010, p. 403), para, assim, diluir fronteiras (GUIZARDI; CAVALCANTI, 2010, p. 1251).

Entre os principais obstáculos identificados para um planejamento intraorganizacional e intersetorialmente integrado destacam-se: (I) a insuficiência de recursos humanos, desencadeando multiplicidade de tarefas; (II) a rotatividade 
de pessoal, impedindo a fluidez ou continuidade do processo, ao se considerarem a perda de capital intelectual e as constantes demandas por capacitação dos profissionais que adentram o serviço; (III) as dificuldades para o estabelecimento de canais de comunicação para a articulação de dados e informações entre o Vigiagua e a VE, devido, principalmente, à prática especializada já arraigada no serviço, e à falta de estímulo político-financeiro para essa articulação; (IV) a priorização de outros programas e campanhas, pela VE, como o combate à dengue e à rubéola, demandas inerentes ao serviço; $(\mathrm{V})$ o processo político e os trâmites burocráticos, comuns na administração pública, e que podem desacelerar, ou mesmo inviabilizar a implantação de estratégias de articulação entre os diferentes departamentos e setores da instância municipal.

A dificuldade em equacionar o grande número de afazeres em função do pequeno número de profissionais ocasiona uma alegada falta de tempo para se programarem ações.

Todo mundo trabalha no limite, então não dá tempo de parar e fazer planejamento. $\mathrm{Eu}$ acho que todo mundo padece dessa falta de pessoal. Eu acho que a falta de pessoal é uma constante, sabe?

No entanto, o ato de planejar pode otimizar o processo de trabalho, minimizando o efeito negativo da relação entre alta demanda de atividades e baixo contingente de profissionais.

No que tange à rotatividade dos profissionais, constatou-se ser este um desafio no cenário em questão para a continuidade de implantação dos processos pactuados, haja vista a renovação de pessoal e a necessidade de constantes capacitações para apropriação da rotina de trabalho pelos ingressos no serviço, além da ruptura de relações interpessoais coesas, e previamente estabelecidas. Esse aspecto pode ser ilustrado pela fala da coordenadora da Vigilância em Saúde Ambiental, que relembra um caso ocorrido em um dos sete distritos trabalhados, no qual todos os profissionais que vinham participando da proposta de interlocução/articulação das Vigilâncias foram substituídos, o que requereu contatar e realizar novas reuniōes com o grupo para reiniciar o processo naquele espaço de atuação.

Pessoal saiu todo mundo, só ficou o administrador regional. A gerente do distrito mudou, as referências técnicas mudaram, por que são as deficiências políticas do município. E isso é uma coisa confusa, por que a gente não sabe por que, né? $\mathrm{E}$ a gente não sabe como é que essa (nova) pessoa vai se comportar lá, né? [...] 
Essa rotatividade pode implicar recorrentes modificações do grupo de trabalho, demandando, assim, a reorganização do processo, com capacitações de pessoal. Consequentemente, os processos de comunicação, as trocas e o aprendizado mútuo, as tentativas de se programar e delegar ações, e ainda, os processos de avaliação para adequações, tudo isso sofre limitaçōes. Identificou-se, ainda, a dificuldade em se realizar um trabalho mais articulado em virtude da existência de demandas internas específicas aos diferentes departamentos envolvidos na rede. A necessidade de atendê-las, muitas vezes em caráter emergencial, pode interromper o fluxo do trabalho conjunto.

Eu acho que não funcionou muito bem, num primeiro momento, porque tinha um descompasso aí, de interesse, sabe? Acho que a VE estava passando por outro momento, devia tá preocupada com dengue, $\mathrm{H} 1 \mathrm{~N} 1$, porque isso tudo rolou, mas é desse jeito mesmo que funciona. Acho que a história da gente ficar apagando incêndio, né gente? Vem H1N1, para tudo que tá fazendo por causa do H1N1. Vem a dengue, para tudo por causa da dengue. Ah... agora tem rubéola? Para tudo [...]. A epidemio, por trabalhar um pouco sob pressão, por causa desse negócio de H1N1, de dengue, de tanta coisa, eles também funcionam um pouco assim, sabe? Menos planejamento, mais ação.

Ademais, foi mencionado como obstáculo para a implantação de novas formas de trabalho mais integrativas o corporativismo da gestão pública.

Características que barram, né? A gestão pública é dominada pelo corporativismo, pelas corporações. Por exemplo, aqui dentro do município, eles trabalham dentro daquela equipe, e ali só vai permitir que entre uma ideia nova, uma coisa nova se não atrapalhar a corporação, se ninguém falar mal deles, se não sinalizar o problema. Porque mostrar a fragilidade da equipe? Entendeu? [...] o governo também vive sob o despotismo da mídia. Então, todos os governos, falou mal deles, eles entram pra dentro da concha, porque não pode, não pode falar, apontar problemas.

Essa necessidade política de julgar pertinente, ou não, a implantação de programas e serviços no âmbito local pode ser justificada pelo fato de essas intervençôes repercutirem em questôes que, em alguns casos, podem ser nocivas para a administração vigente, como, por exemplo, a detecção de formas de abastecimento de água contaminada, que demanda intervenções imediatas por parte do governo, mas nem sempre planejadas ou factíveis. Identificou-se como necessário, portanto, que os gerentes distritais compreendam a proposta de integração e sua magnitude, para que, já cientes de suas implicações, permitam que discussões, elaboração e pactuações de estratégias sejam iniciadas, junto aos atores locais. 
Quando a diretora do distrito, que é um cargo político... se ela entender que não vai ter nenhuma intercorrência política - leve o tempo que levar: um mês, dois, seis, um ano - na hora que ela entender que não vai ter problema, ela faz. Ela deixa a gente fazer. Mas tem que passar por ela, por isso que o tempo é diferente. [...] Então isso ocorre no município o tempo todo: política administrativa, né? [...]

Constitui-se, portanto, em meta inicial para a implantação de estratégias articuladoras, na instância local (ou distrital), apresentar a proposta de trabalho para o gerente (ou outro responsável), da instância em que se propõe a atuar. As reuniōes nas quais foram abordadas as propostas de interação, visando às ações articuladas, foram realizadas inicialmente com o gerente distrital, e com o seu aval partiu-se para a conversa com o comitê gestor de cada Distrito Sanitário de Saúde (DSS). Após as deliberações em grupo, novos encontros foram promovidos, com a participação dos profissionais da rede de saúde, o que, de acordo com a seguinte fala:

[...] permitiu que [a proposta de integração de dados e articulação entre vigilâncias] não ficasse na mão de uma gerência, mas fosse apropriada pela comunidade, pela rede. É uma garantia que o trabalho vai ter continuidade, que vai ser mais permanente. [...] Para ter a rede, né? Por que é isso que a gente pensa. Ter uma rede. E a rede sempre tem uma ponta inicial, aonde [sic] começa, mas depois tem que ter, tem que ser uma rede, né?

A tabela 1 compila os aspectos motivadores, facilitadores e dificultadores para a implantação da proposta de articulação intraorganizacional e intersetorial identificados e que podem interferir no tecer dessa rede na instância municipal.

Tabela 1. Fatores condicionantes da interlocução entre Vigiagua e Vigilância Epidemiológica

\begin{tabular}{|c|c|c|}
\hline Aspectos motivadores & Aspectos facilitadores & Aspectos dificultadores \\
\hline $\begin{array}{l}\text { Cumprimento de metas } \\
\text { ministeriais; } \\
\text { Perspectiva de um } \\
\text { processo de trabalho mais } \\
\text { eficiente; } \\
\text { Valorização do trabalho; } \\
\text { Maior domínio sobre o } \\
\text { trabalho executado; } \\
\text { Expectativa de } \\
\text { agregar outras áreas e } \\
\text { conhecimentos; }\end{array}$ & $\begin{array}{l}\text { Desejo de aprimorar o } \\
\text { processo de trabalho; } \\
\text { Possibilidade de } \\
\text { descentralizar o } \\
\text { planejamento, aproximando } \\
\text { nível central e nível executor } \\
\text { das açôes; } \\
\text { Conhecimento para } \\
\text { apropriação do trabalho; } \\
\text { Desejo de trabalhar em rede. }\end{array}$ & $\begin{array}{l}\text { RH insuficiente; } \\
\text { Alta rotatividade de profissionais } \\
\text { no serviço; } \\
\text { Dificuldade de estabelecimento } \\
\text { de canais de comunicação coesos; } \\
\text { Dificuldade de estabelecimento } \\
\text { do nexo causal entre água } \\
\text { consumida e morbidades; } \\
\text { Inexistência de planejamento de } \\
\text { açóes pelos departamentos; } \\
\text { Processo político e administração } \\
\text { pública municipal; }\end{array}$ \\
\hline
\end{tabular}

Fonte: os autores. 
É possível afirmar que inexiste, entre gestores e profissionais que atuam na esfera municipal, uma cultura sobre métodos para programar o trabalho dialógico e interativo que privilegiem instâncias de mediação, espaços protegidos e processos de contrato em que se estabeleçam metas e critérios para avaliação de trabalho (CAMPOS; DOMITTI, 2007, p.405). Para Leischow et al. (2008), tanto a inexistência desses espaços como a não disponibilização de informações intraorganizacionais e intersetoriais impedem um planejamento integrado efetivo.

Como possível explicação, Heller e Castro (2007, p. 290) afirmam que as práticas de gestão ou organização dos serviços, no âmbito do município, podem ser diretamente influenciadas pelos processos políticos e econômicos e por importantes fatores culturais - como a cultura política dominante - que ora podem facilitar, ora dificultar a adoção de determinada política. Os mesmos autores salientam a disfunção crônica dos arranjos institucionais existentes no âmbito municipal que podem interferir, sobremaneira, na operacionalização do planejamento integrado: capacidade institucional inadequada, incentivos não apropriados, desconsideração na prestação de contas à comunidade, entre outros.

As relaçōes interpessoais, profissionais e políticas também fazem parte do processo de consolidação dessas estratégias de comunicação para a articulação intersetorial e devem ser consideradas. $\mathrm{O}$ estabelecimento dessas relaçōes requer que se estimulem os gestores a se organizarem matricialmente, de forma a oferecer assessoria técnica às unidades de prestação de serviços (capacitação, prestação de informações, etc.), promovendo, também, reuniões periódicas para discussão dos dados e planejamento de ações.

O encorajamento da atuação dos comitês gestores - órgãos bastante atuantes e efetivos nesse município - também se mostra adequado, pois privilegia a participação de epidemiologistas, profissionais da atenção básica, administradores regionais, membros representantes da sociedade civil, órgãos sociais e da educação, em uma estrutura coesa. Assim, o estabelecimento de espaços coletivos de comunicação e planejamento integrado perpassa por estratégias de democratização das relações de poder, e de superação das capacidades assimétricas de decisão (BUEHLER, 1998; GUIZARDI; CAVALCANTI, 2010, p.1249). $\mathrm{O}$ estímulo para a interlocução entre as vigilâncias deve ser contínuo, o que demanda capacitação e desejo dos profissionais para esse exercício. 
No caso específico desta pesquisa-ação, visando amalgamar os dados e as informações advindas das diferentes áreas, revelou-se inicialmente necessário identificar as potenciais parcerias no serviço, assim como o desejo e o interesse desses parceiros em atuar de forma interativa. Portanto, conforme revelam Bate et al. (2000), em virtude de o comportamento e a atuação do profissional pautaremse pela realidade da organização a que ele pertence, tornou-se necessário um entendimento mútuo sobre os contextos de atuação, bem como os instrumentos disponíveis nos diversos campos de trabalho envolvidos. Reuniões de integração, realizadas nos níveis central e local comprovaram-se ferramentas úteis para angariar parceiros e compartilhar conhecimentos.

No entanto, é necessário ressaltar que raramente um programa é igualmente efetivo em todos os locais onde é implantado, o que pode ser atribuído, principalmente, às influências do contexto, tais como comportamentos, crenças, valores, fatores socioeconômicos e educacionais, entre outros. É preciso ter como premissa a necessidade de avaliaçōes e discussões sistemáticas para gerar um consenso acerca as melhores formas de abordagem, segundo as especificidades identificadas no contexto em que se deseja intervir.

\section{Considerações finais}

Apesar de os problemas relacionados à água para consumo humano manifestaremse setorialmente, é possível afirmar que sua solução demanda uma atuação integrada de atores advindos de diferentes setores. A qualidade e a disponibilidade da água, direta e indiretamente, influenciam e são influenciadas por diversas políticas setoriais, além da saúde, como a educação, o saneamento, a habitação, agricultura, desenvolvimento econômico, etc.

No contexto dessa pesquisa-ação, identificou-se que seminários e reuniōes realizadas caracterizaram-se como espaços de interação dialógica que possibilitaram aos profissionais da rede e demais atores envolvidos conhecer seu território de atuação, estabelecer parcerias, identificar e compartilhar informações, indicadores e instrumentos disponíveis e utilizados. Esses espaços possibilitaram, ainda, uma aproximação entre gestores do nível central e "executores" das instâncias locais, com a difusão da proposta e das estratégias moldadas ao contexto da intervenção. Esse momento de compartilhamento de 
informações para o planejamento integrado constitui importante instrumento para definição de prioridades, direcionamento de estratégias e efetivação de ações necessárias para a integralidade e equidade das políticas sociais (TEIXEIRA; PAIM, 2000).

No entanto, convém destacar que os resultados aqui apresentados são fruto de uma pesquisa advinda de uma demanda externa, oriunda do Ministério da Saúde, articulada por meio de uma pesquisa-ação que contou com a participação de pesquisadores externos e colaboradores do serviço municipal. A organização dessas reuniões para discussão do processo de planejamento integrado entre as vigilâncias partiu, em princípio, dos coordenadores da pesquisa, havendo, também, uma disponibilidade interna para atuar na construção dessas estratégias, previamente pactuada com os membros do serviço. Cabe, portanto, indagar: como despertar o serviço para a necessidade de integração entre indicadores gerados pelas vigilâncias, e outros departamentos, quando se busca um planejamento conjunto de ações? Como e em que momento o serviço despertará para a necessidade de se organizar para atuar de forma articulada? Como sensibilizar gestores e profissionais para a necessidade de confrontarem seu já conhecido modus operandi e buscar novas estratégias de atuação quando, por vezes, imperam a falta de autonomia e a impotência no tomar de decisóes?

Uma vez constatado que os profissionais da rede reconhecem a importância da atuação integrada no âmbito do serviço, questiona-se ainda: como despertar gestores para que passem a privilegiar e valorizar o trabalho articulado entre diferentes departamentos e setores no âmbito do serviço? Ou, ainda, seria sempre necessário despertar os gestores para então estimular a articulação intraorganizacional?

Nasaúde, área complexa por natureza, a fragmentação das responsabilidades pode equivaler à integração dos problemas. Ou seja, a perpetuação de uma abordagem segmentada pode consolidar intervenções fracionadas e descontextualizadas. Um novo olhar e um novo agir sobre a realidade, privilegiando a comunicação e a tomada de decisão de forma democrática e articulada são mais que necessários, quando se busca a promoção da saúde da população ${ }^{1}$ 


\section{Referências}

BATE, P.; KHAN, R.; PYE, A. Towards a culturally sensitive approach to organization structuring: where organization design meets organization development. Organization Science, v.11, n.2, p.197-211, 2000.

BESSELAAR, P. Van den; HEIMERIKS, G. Disciplinary, multidisciplinary, interdisciplinary concepts and indicators. Paper for the 8th conference on Scientometrics and Informetric, 2001. BRASIL. Fundação Nacional de Saúde. Centro Nacional de Epidemiologia. Coordenação Geral de Vigilância Ambiental em Saúde. Sistema Nacional de Vigilância Ambiental em Saúde. Brasília: Ministério da Saúde, 2003. 32p.

BUEHLER, J. Surveillance. In: ROTHMAN, K.J.; GREENLAND, S. Modern epidemiology. 2 ed. Philadelphia: Lippicott-Raven, 1998, p. 435-458.

CAMPOS, G.W.S. Cogestão e neoartesanato: elementos conceituais para repensar o trabalho em saúde combinando responsabilidade e autonomia. Ciência e saúde coletiva, v.15, n.5, p.2337-2344, 2010.

CAMPOS, G.W.S.; DOMITTI, A.C. Apoio matricial e equipe de referência: uma metodologia para gestão do trabalho interdisciplinar em saúde. Cad. Saúde Pública, v.23, n.2, p.399-407, 2007.

GUIZARDI, F.L.; CAVALCANTI, F.O.L. O conceito de cogestão em saúde: reflexões sobre a produção de democracia institucional. Physis: Revista de Saúde Coletiva, v.20, n.4, p.1245-1265, 2010.

HABERMAS, J. Consciência moral e agir comunicativo. In: Consciência moral e agir comunicativo. Rio de Janeiro: Tempo Brasileiro, 2003. p.143-233.

HELLER, L.; CASTRO, J.E. Política pública de saneamento: apontamentos teóricoconceituais. Revista de Engenharia Sanitária e Ambiental, v.12, p.284-295, 2007.

JUNQUEIRA, L.A.P. Novas formas de gestão na saúde: descentralização e intersetorialidade. Saúde e Sociedade, v.6, n.2, p.31-46, 1997.

LEISCHOW, S.J.; BEST, A.; TROCHIM, W.M.; CLARK, P.I.; GALLAGHER, R.S.; MARCUS, S.E.; MATTHEWS, E. Systems thinking to improve the public's health. American Journal of Preventive Medicine, v.35, n.2 (supl.), p.S196-203, 2008.

LEWIN, K. Action research and minority problems (1946/1948). In: LEWIN, G.W. Resolving social conflicts. New York: Harper \& Row, p.201-216.

LIMA, J.C.; RIVERA, F.J. Agir comunicativo, redes de comunicação e coordenação em serviços de saúde. Interface, v.3, n.31, p.329-342, 2009. 
MAGALHAES, R.; BODSTEIN, R. Evaluation on initiative and intersectorial programs in health: challenges and learning. Ciência e Saúde Coletiva, v.3, n.14, p.861-868, 2006.

MELO, E.M. Ação comunicativa, democracia e saúde. Ciência e Saúde Coletiva, v.10 (supl.), p.167-178, 2005.

MERRIAN, S.B. Qualitative research a guide to design and implementation. San Francisco: Jossey-Bass, 2009, 304 p.

MORAN, M. Interdisciplinarity and Political Science. Politics, v.26, n.2, p.73-83, 2006.

RIVERA, F.J.U.; ARTMANN, E. Planejamento e gestão em saúde: histórico e tendências com base numa visão comunicativa. Ciência e Saúde Coletiva, v.15, n.5, p.2265-2274, 2010.

RIVERA, F.J.U.; ARTMANN, E. Planejamento e gestão em saúde: flexibilidade metológica e agir comunicativo. Ciência e Saúde Coletiva, v.4, n.2, p.355-365, 1999.

TEIXEIRA, C.F.; PAIM, J.S. Planejamento e programação das açôes intersetoriais para a promoção da saúde e da qualidade de vida. Revista de Administração Pública, v.34, p.63-80, 2000.

THIOllent, M. Metodologia da pesquisa-ação. 16ª ed. São Paulo: Cortez, 2008. 132 p.

TRIPP, D. Pesquisa-ação: uma introdução metodológica. Educação e Pesquisa, v.31, n.3, p.443-466, 2005.

\section{Nota}

${ }^{1}$ A.C.L. Queiroz propôs o tema desenvolvido, realizou o levantamento bibliográfico, a pesquisa empírica e a primeira versão do artigo. L.S.M. Cardoso participou da realização da pesquisa empírica e da redação do artigo. M.T.Z. Coutinho e F.A. Guimarães participaram da pesquisa empírica, revisão do texto e da elaboração da versão final. L. Heller participou da discussão teórico-metodológica, da revisão do texto e da elaboração da versão final. Todos os autores discutiram, leram e aprovaram a versão final do artigo. 
Water and health: (dis)integration of surveillance and the lessons of practice

The integration of intra and inter-sectoral actions in health care is a challenge for municipal managers, once fragmented data generation and analysis of dissociated information prevail in the daily practice of the service, resulting in barriers to integrated planning. A possible path to that desired functional integration permeates the establishment of permanent communication channels, enabling the joint programming of interventions involving different departments and sectors. An evaluation of the process of articulation between the epidemiological surveillance and environmental health related to drinking water (Vigiagua), developed in the municipality of Contagem-MG, identified through content analysis of interviews with the coordination of the Environmental Health Surveillance, the factors that interfere with their institutionalization. The search for greater appreciation of the work area and by professionals of the Vigiagua, and the expectation of bringing together different agents and areas of expertise in solving common problems were identified as key drivers and facilitators of the process. Still, the obstacles identified were: human and financial resources; inadequate materials; lack of technical and managerial autonomy to establish cohesive communication channels; and incipient planning practice in the service. Seminars and meetings were characterized as spaces of interaction and dialogue in the service and allowed an approximation of central-level managers to "executors" of local authorities. However, the stimulus to this dialogue should be continuous, which requires training and desire of managers and professionals for this exercise.

Key words: evaluation of health programs and projects; planning; programming; integration of systems; surveillance. 